\title{
A Case of Posterior Semicircular Canal Dehiscence Caused by High Jugular Bulb
}

\author{
Sung-Won Choi, Soo-Keun Kong, Eui-Kyung Goh, and Se-Joon Oh \\ Department of Otorhinolaryngology-Head and Neck Surgery, Pusan National University School of Medicine and \\ Medical Research Institute, Busan, Korea
}

\section{고위 경정맥구에 의한 후반고리관 피열 1예}

최성원 · 공수근 · 고의경 · 오세준

부산대학교 의학전문대학원 이비인후과학교실

\author{
Received December 20, 2016 \\ Revised February 20, 2017 \\ Accepted February 23, 2017 \\ Address for correspondence \\ Se-Joon Oh, MD, PhD \\ Department of Otorhinolaryngology- \\ Head and Neck Surgery, \\ Pusan National University \\ School of Medicine and \\ Medical Research Institute, \\ 179 Gudeok-ro, Seo-gu, \\ Busan 49241, Korea \\ Tel $+82-51-240-7336$ \\ Fax $+82-51-246-8668$
}

E-mailo3jdoc@hanmail.net
Posterior semicircular canal dehiscence represents a third-window lesion manifesting as hearing loss with vestibular dysfunction. Computed tomography findings of a dehiscent posterior canal can be verified with increased vestibular evoked myogenic potential responses as in other third-window lesions. The jugular bulb is the bulbiform connection between the sigmoid sinus and the internal jugular vein at the skull base. High jugular bulb can erode into inner ear structures. According to the literature review, there has been no case report about posterior semicircular canal dehiscence caused by high jugular bulb in Asia. Therefore, the authors report a case with a review of literature.

Korean J Otorhinolaryngol-Head Neck Surg 2018;61(8):435-8

Key Words High jugular bulb · Posterior semicircular dehiscence.

\section{서 론}

고위 경정맥구는 와우의 기저회전(basal turn)보다 높거나 ${ }^{1)}$ 골부 고실륜보다 높게 경정맥구가 돌출된 경우를 말한다. ${ }^{2)}$ 고 위 경정맥구로 인한 증상은 병변의 범위와 위치에 따라 다양 하며 청력소실, 이명, 어지럼 등으로 나타난다.3)

후반고리관 피열 증후군(posterior semicircular canal dehiscence syndrome)은 상반고리관 피열에 이어 보고된 바 있 으며, 상반고리관 피열에서 나타나는 이충만감이나 자가강청 과 같은 여러 청각증상과 유사한 증상이 동반된다." 청력소 실의 경우 경도 전도성 난청에서부터 고도 감각신경성 난청까 지 다양하게 나타난다고 알려져 있다. ${ }^{5}$ 후반고리관 피열은 고

This is an Open Access article distributed under the terms of the Creative Commons Attribution Non-Commercial License (https://creativecommons.org/licenses/by-nc/4.0) which permits unrestricted non-commercial use, distribution, and reproduction in any medium, provided the original work is properly cited.
위 경정맥구와 관계가 있다고 보고되었는데, ${ }^{5,6)}$ 아직 국내 및 아시아에서 보고된 바는 없어 저자들은 고위 경정맥구(high jugular bulb)가 원인이 된 후반고리관 피열을 확인하여 보고 하고자 한다.

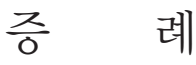

45세 여자 환자가 내원 약 1년 전부터 소음을 들으면 어지럽 고, 우측의 박동성 이명을 호소하며 내원하였다. 환자는 내원 당시 난청, 이통, 이루, 이충만감 등의 증상은 호소하지 않았고, 고혈압으로 약물치료 중이었으며 그 외 당뇨, 간염, 결핵, 매독 등의 질환은 동반하지 않았다.

환자의 이명 설문지 검사상 0 10점의 Visual Analog Scale 에서 이명 지속시간은 10점, 이명 크기는 6점, 이명으로 인한 괴로움 7점, 생활에 미치는 영향은 5점, 수면을 제외한 하루 
중 이명을 느끼는 시간은 $100 \%$ 로 박동성 이명으로 인해 일상 생활을 하는 데에 있어서 불편감을 호소하였다.

내원 당시 시행한 신체검사상 양측 고막의 특이소견은 관 찰되지 않았고, 우측 경부를 압박하면 환자가 느끼는 이명이 소실되는 양상을 보였다. 신경학적인 검사상에서 특이소견은 없었고 안진검사에서도 특이소견은 보이지 않았으며 누공검 사(fistula test)에서도 음성이었다.
순음청력검사상 양측 귀 모두 저음역에서 기도-골도차가 $10 \mathrm{~dB}$ 정도로 확인이 되었고(Fig. 1), 고막운동성검사상 양 측 귀 모두 $\mathrm{A}$ 형이었으며, 전정유발근전위(vestibular evoked myogenic potentials, VEMP) 검사 결과 좌측의 역치 $75 \mathrm{~dB}$ 에 비해 우측에서는 $65 \mathrm{~dB}$ 로 역치가 낮았다(Fig. 2).

그 외 어음명료도 검사에서는 우측 $75 \mathrm{~dB}$ 에서 $96 \%$, 좌측 $60 \mathrm{~dB}$ 에서 $100 \%$ 의 어음명료도를 보였고, 이음향방사검사는

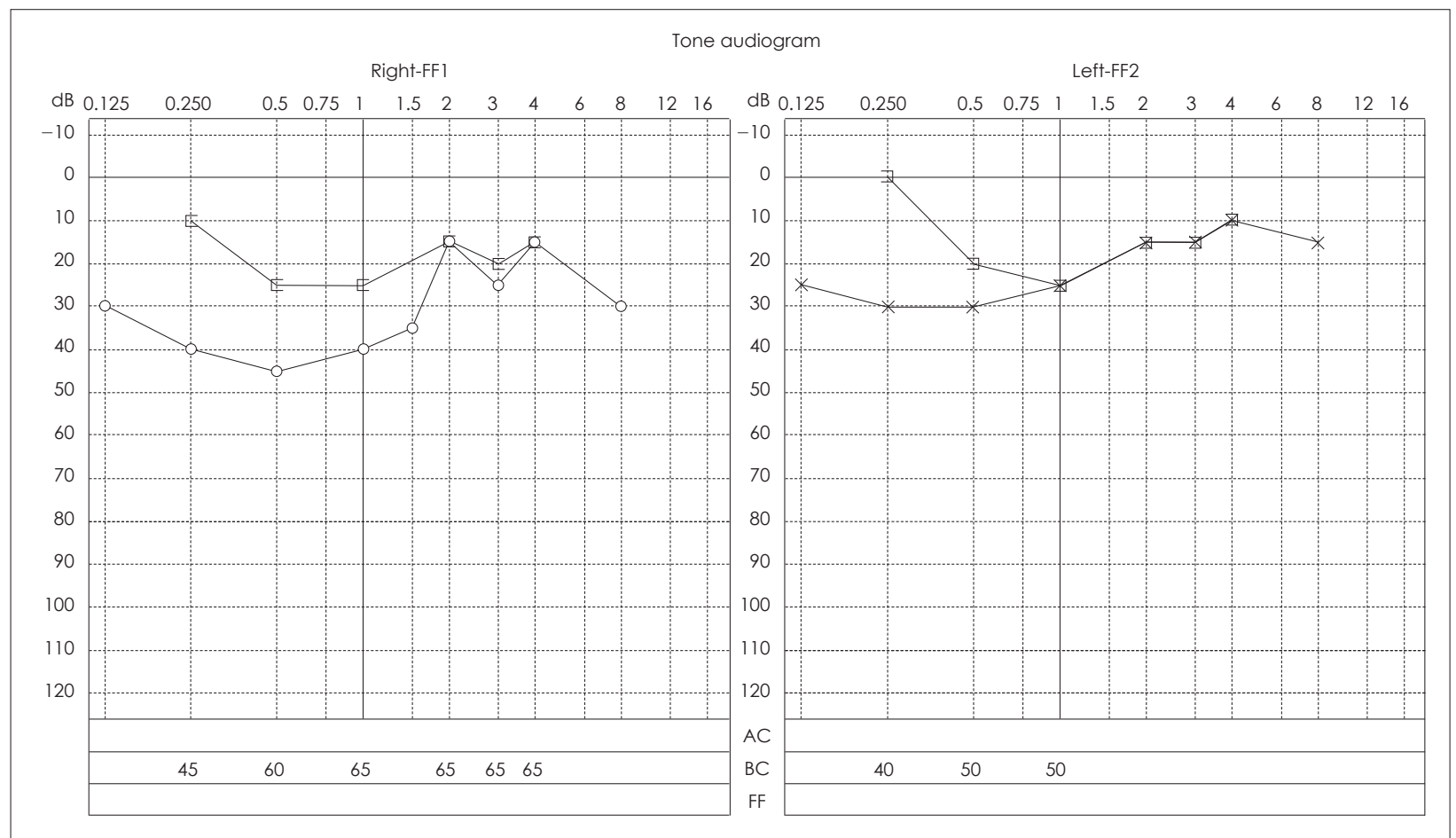

Fig. 1. Pure tone audiogram shows air-bone gap at the low frequencies in both ears.

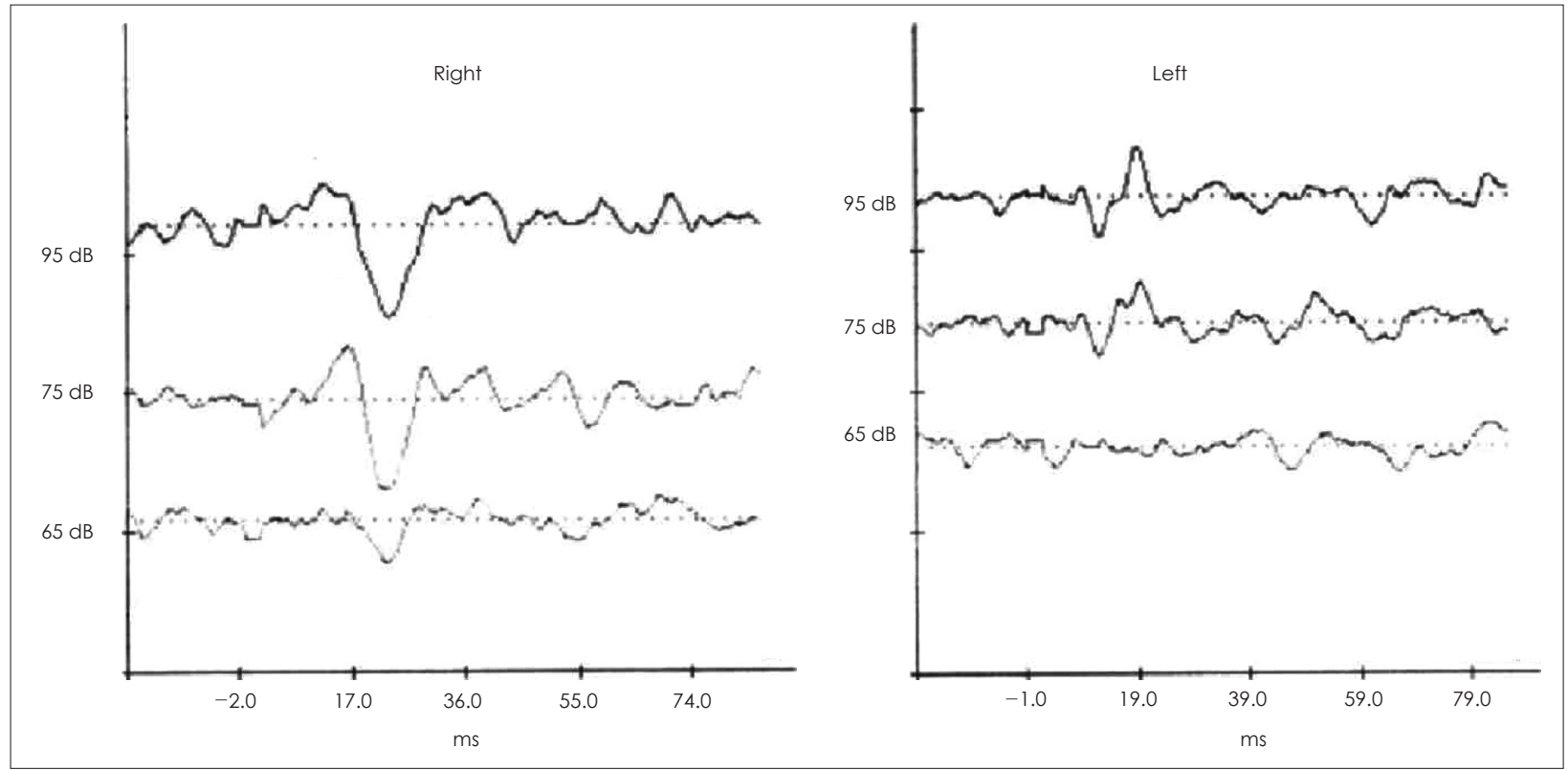

Fig. 2. Vestibular evoked myogenic potentials. The threshold of right side is lower than that of the left side. 

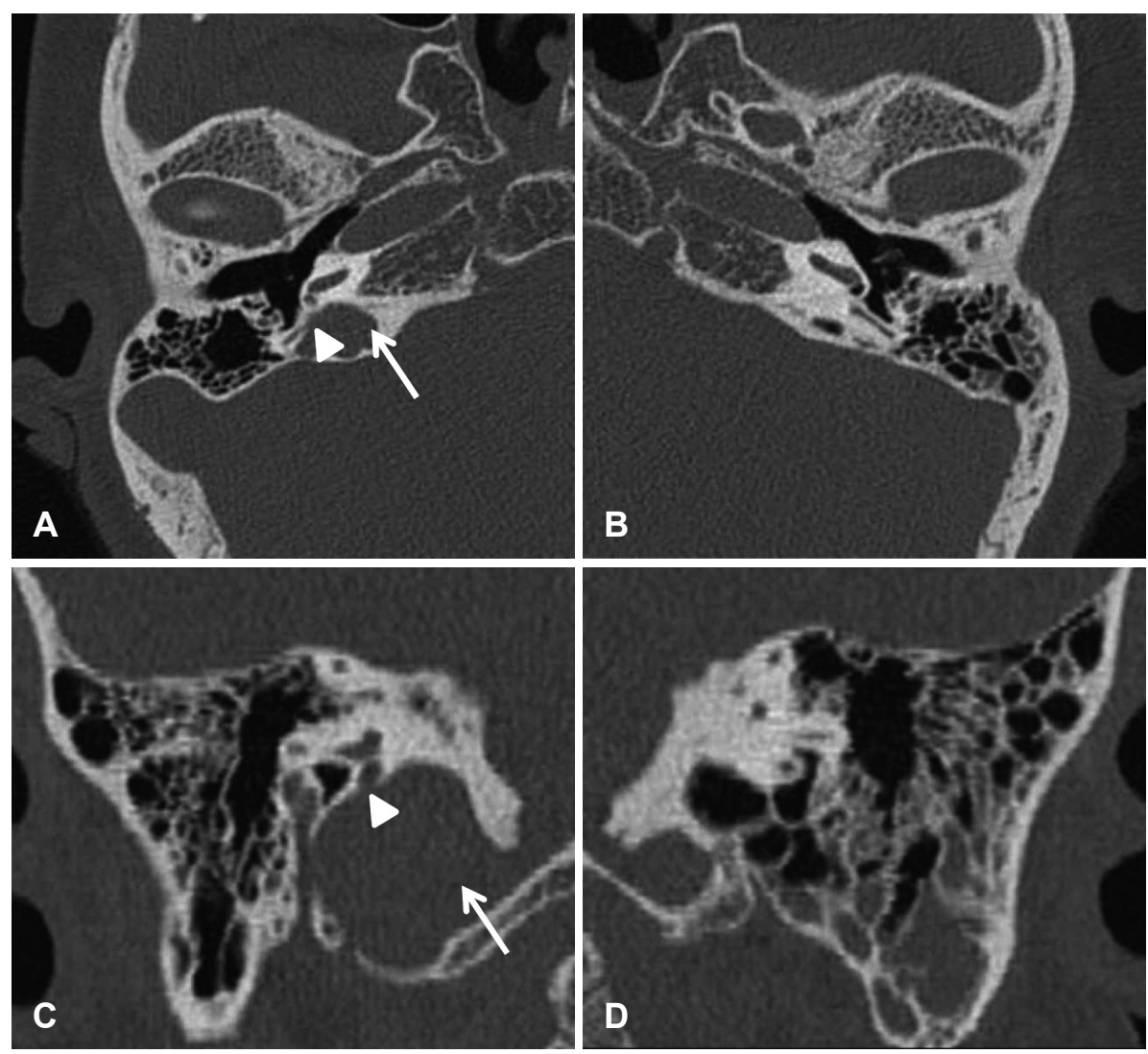

Fig. 3. Right side temporal bone $\mathrm{CT}$ axial image shows high riding jugular bulb (arrow) in contact with the posterior semicircular canal (arrowhead) (A). Left side temporal bone $\mathrm{CT}$ image shows absence of jugular bulb abnormality and intact posterior canal (B). Right coronal image shows high riding jugular bulb (arrow) in contact with the posterior semicircular canal (arrowhead) (C). Left coronal image (D).

정상소견을 보였다. 상반고리관 피열을 의심하고 측두골 전 산화단층촬영을 시행하였는데, 상반고리관 피열은 없었고, 고 위 경정맥구로 후반고리관이 피열되어 있는 것을 확인할 수 있었다(Fig. 3).

\section{고 찰}

반고리관의 피열은 Minor 등ㄱㅇㅔ 의해 상반고리관의 피열로 1998년에 처음 보고되었다. 반고리관 피열의 원인에 대해서 는 아직까지 명확히 밝혀져 있지는 않지만 선천적인 해부학적 요소와 압력, 염증과정에 의해 영향을 받는 것으로 알려져 있 다. 예를 들어 상반고리관 피열은 증가된 뇌압에 의해, 측반고 리관 피열은 만성중이염 및 진주종의 영향을 받는 것으로 알 려져 있다. ${ }^{8}$ 후반고리관 피열은 상반고리관 및 측반고리관 피 열과 다르게 고위 경정맥구 및 섬유이형성증과 관련이 있다 고 알려져 있다.,10)

반고리관 피열은 제 3 의 창의 생성을 야기하며 청각기관과 전정기관의 기능이상을 야기한다. 청각기능이상은 청력저하, 이명, 자가강청을 포함하며 이때의 청력저하는 혼합성 난청 이나 감각신경성 난청, 전도성 난청의 형태로 나타나기도 한 다. 전도성 난청일 때는 마치 중이 질환으로 인한 이소골의 병
변인 것처럼 보이기도 하는데, 이소골의 병변에서 VEMP 결 과는 소실되거나 역치가 증가함으로 반고리관 피열과 구분될 수 있다. ${ }^{5)}$ 이명은 대개 박동성이나 비박동성으로 나타나기도 하며 환자들은 심장박동, 안구 움직임, 자신의 음성이 증폭 된 소리를 듣기도 한다. 전정기능이상은 만성적인 자세불균형, Tullio phenomenon, 어지럼을 포함한다. ${ }^{5}$

후반고리관 피열은 고위 경정맥구와 관계가 있다고 보고되 었는데 정맥구의 형성과 발달은 사람의 자세 및 혈역학적 변동 과 긴밀한 관계가 있으며, 특히 정맥의 높은 압력과 turbulent flow가 고위 경정맥구 형성의 원인으로 알려져 있다.11) 본 증례 에서도 고위 경정맥구 높은 압력과 turbulent flow로 인하여 인접한 후반고리관의 골부가 얇아지게 되어 피열을 초래할 소 지가 있다고 생각된다.

임상적으로 의심이 될 경우 CT scan으로 피열을 확인할 수 있으나, 영상학적인 검사만으로는 위양성의 가능성이 있고, 골편의 두께가 0.1 0.2 mm밖에 안된다면 기능적인 피열이 있는지를 확인하는 것이 중요하다. 청력검사 시 병변측의 저 주파수에서 기도-골도차가 관찰되며, 이는 고막진동을 통해 내이로 전달된 소리에너지가 제 3 의 창을 통해 분산되어 공기 전도 청력역치가 상승하는데에 반해, 뼈전도에 의한 진동에 너지는 림프액의 진동을 더 쉽게 유발하여 뼈전도 청력의 역 
치가 낮아지기 때문이다. ${ }^{12)}$ 고위 경정맥구에서도 반고리관 피 열에서처럼 저음역에서 기도-골도차를 관찰할 수 있으며, 본 증례에서는 양측 저음역에서 기도-골도차가 관찰되었고, 측 두골 전산화단층촬영을 시행하여 병변측에서 고위 경정맥구 로 후반고리관이 피열되어 있는 것을 확인하였다. VEMP가 이소골의 병변과 반고리관 피열을 구분하는 데 도움이 되는 데, 중이 질환으로 인한 이소골의 병변에서는 $\mathrm{VEMP}$ 가 형성 되지 않거나 역치가 증가하는데에 반해, 반고리관 피열의 경우 진폭은 커지고 역치는 줄어드는 차이가 있다. ${ }^{13)}$ 본 증례에서 도 $\mathrm{VEMP}$ 검사 결과 좌측의 역치 $75 \mathrm{~dB}$ 에 비해 우측에서는 65 $\mathrm{dB}$ 로 역치가 낮았으며, 이는 구형낭이 소리자극에 더 민감해져 있음을 의미하고, 같은 크기의 소리자극이라도 난원창으로 전 달된 진동은 반고리관에 형성된 제 3 의 창으로 인해 전정부와 반고리관으로의 림프액의 움직임이 증가하기 때문으로 이해할 수 있다. ${ }^{14)}$

후반고리관 피열 증후군의 치료는 우선 주관적 증상이 일 상생활에 큰 불편함을 주지 않을 경우 유발 자극의 회피 등의 보존적 치료가 도움이 될 수 있다. 증상이 심할 경우 수술적 치 료를 고려해 볼 수 있는데, 수술적 치료로는 유양동접근술을 통해 골피판이나 근막을 이용하여 피열 부위를 덮어주는 방법 (resurfacing) ${ }^{15)}$ 이나 피열 부위를 폐쇄(plugging)하는 방법 ${ }^{6}$ 이 있다. 또한 후반고리관 피열은 고위 경정맥구와 동반하는 경우가 많기 때문에 고위 경정맥구 색전술 혹은 내경정맥결 찰술 등을 시도해 볼 수 있다. 본 증례에서는 수술적 치료를 권유하였으나, 환자 및 보호자가 수술적 치료를 원하지 않아 유발 자극의 회피 등의 보존적 치료로 경과 관찰을 하였다.

고위 경정맥구는 비교적 흔하나 이로 인한 후반고리관 피열 은 극히 드문 경우로 저자들은 고위 경정맥구에 의한 후반고 리관 피열에 의해 어지럼 및 이명을 호소한 증례를 국내 및 아 시아에서 첫 번째로 보고하는 바이다. 후반고리관 피열과 이소 골 병변을 구분하는 것이 중요한데, CT와 VEMP가 진단에 도움이 될 수 있다. 결론적으로 본 증례와 같이 자극에 의한 현훈, 저음역 전도성 난청, 박동성 이명이 있을 경우 드물기는 하지만 반고리관 피열도 임상적으로 의심해 볼 필요가 있다.

\section{Acknowledgments}

This work was supported by clinical research grant from Pusan National University Hospital in 2018.

This work was supported by the National Research Foundation of Korea (NRF) grant funded by the Korea government (MSIP) (No. 2016R1D1A1B03932026).

\section{REFERENCES}

1) Wadin $K$, Thomander L, Wilbrand H. Effects of a high jugular fossa and jugular bulb diverticulum on the inner ear. A clinical and radiologic investigation. Acta Radiol Diagn (Stockh) 1986;27(6): 629-36.

2) Hourani R, Carey J, Yousem DM. Dehiscence of the jugular bulb and vestibular aqueduct: findings on 200 consecutive temporal bone computed tomography scans. J Comput Assist Tomogr 2005;29(5): 657-62.

3) Weiss RL, Zahtz G, Goldofsky E, Parnes H, Shikowitz MJ. High jugular bulb and conductive hearing loss. Laryngoscope 1997;107 (3):321-7.

4) Krombach GA, DiMartino E, Schmitz-Rode T, Prescher A, Haage $\mathrm{P}$, Kinzel S, et al. Posterior semicircular canal dehiscence: a morphologic cause of vertigo similar to superior semicircular canal dehiscence. Eur Radiol 2003;13(6):1444-50.

5) Gopen Q, Zhou G, Poe D, Kenna M, Jones D. Posterior semicircular canal dehiscence: first reported case series. Otol Neurotol 2010;31(2): 339-44.

6) Mikulec AA, Poe DS. Operative management of a posterior semicircular canal dehiscence. Laryngoscope 2006;116(3):375-8.

7) Minor LB, Solomon D, Zinreich JS, Zee DS. Sound- and/or pressureinduced vertigo due to bone dehiscence of the superior semicircular canal. Arch Otolaryngol Head Neck Surg 1998;124(3):249-58.

8) Schutt CA, Kveton JF. Posterior semicircular canal dehiscence secondary to jugular enlargement. Am J Otolaryngol 2016;37(3): 173-4.

9) McCall AA, Curtin HD, McKenna MJ. Posterior semicircular canal dehiscence arising from temporal bone fibrous dysplasia. Otol Neurotol 2010;31(9):1516-7.

10) Spasic M, Trang A, Chung LK, Ung N, Thill K, Zarinkhou G, et al. Clinical characteristics of posterior and lateral semicircular canal dehiscence. J Neurol Surg B Skull Base 2015;76(6):421-5.

11) Friedmann DR, Eubig J, McGill M, Babb JS, Pramanik BK, Lalwani AK. Development of the jugular bulb: a radiologic study. Otol Neurotol 2011;32(8):1389-95.

12) Suh MW, Jeong SH, Kim JS. Vestibular evoked myogenic potential: recording methods and clinical application. J Korean Neurol Assoc 2010;28(1):1-12.

13) Welgampola MS, Colebatch JG. Characteristics and clinical applications of vestibular-evoked myogenic potentials. Neurology 2005;64(10): $1682-8$

14) Koo JW. Superior semicircular canal dehiscence syndrome. Korean J Otorhinolaryngol-Head Neck Surg 2011;54(2):117-23.

15) Gubbels SP, Zhang Q, Lenkowski PW, Hansen MR. Repair of posterior semicircular canal dehiscence from a high jugular bulb. Ann Otol Rhinol Laryngol 2013;122(4):269-72. 